\title{
Educational level as a predictor of the incidences of non-communicable diseases among middle-aged Japanese: a hazards- model analysis
}

\author{
Takashi Oshio ${ }^{1 *}$ (D) and Mari Kan²
}

\begin{abstract}
Background: It is well known that there are educational inequalities in incidences of non-communicable diseases (NCDs). Unlike most preceding studies, this study examined this issue using a hazards model analysis, with specific reference to the potential mediating effects of socioeconomic status (SES), other than educational level, and health behaviour as well as gender differences.

Methods: Data were obtained from a 12-wave longitudinal nationwide survey conducted from 2005 to 2016 with middle-aged individuals in Japan. Participants included 31,210 individuals (15,127 men and 16,083 women) who were aged 50-59 years at wave 1. Incidences of six NCDs (diabetes, heart disease, stroke, hypertension, hyperlipidaemia, and cancer), initially diagnosed between waves 2 and 12, were considered. Cox proportional hazards models were estimated to examine their associations with educational level, adjusted for baseline SES and health behaviour. Educational inequalities were measured by the relative indices of inequality (RII).
\end{abstract}

Results: Lower educational level was associated with higher incidences of diabetes and stroke among both men and women, and with hypertension only among women. After controlling for baseline SES, health behaviour, and regional areas, the RII ranged from 1.37 (95\% confidence interval [Cl]: 1.02-1.85) for stroke among men to 2.65 (95\% Cl, 2.093.36) for diabetes among women. Small to moderate parts (0.0-32.7\%) of the RII were explained by baseline SES and health behaviour. A negative association with education was observed for diabetes and hypertension among women.

Conclusions: Results underscored the importance of educational level as a predictor of the incidences of selected NCDs, especially among women, with limited mediating effects of other SES and health behaviour.

Keywords: Educational level, Hazards model, Relative index of inequality, Non-communicable diseases

\section{Background}

It is well known that health outcomes are closely related to educational level [1]. Specifically, lower levels of education have been found to be related to higher incidence and prevalence of non-communicable diseases (NCDs) $[2,3]$-including cardiovascular and cerebrovascular diseases [4-7], cancers [8, 9], diabetes [10-12], hypertension [13], and chronic respiratory diseases [14] -in addition to higher levels of cause-specific and all-cause

\footnotetext{
* Correspondence: oshio@ier.hit-u.ac.jp

${ }^{1}$ Institute of Economic Research, Hitotsubashi University, 2-1 Naka, Kunitachi,

Tokyo 186-8603, Japan

Full list of author information is available at the end of the article
}

mortality [15-17]. However, most of the preceding studies on educational inequalities in NCD incidence have been prospective cohort analyses, which focused on the prevalence or cumulative incidence over the follow-up period among respondents with no baseline disease (e.g. [5, 11, $14]$ ), or (repeated) cross-sectional analyses, which compared the prevalence of the diseases among respondents with different levels of educational attainment (e.g. [2, 4, 6, $18])$. In comparison, hazards model analyses, which aimed to relate the time passage before the incidence of the disease to educational level, have been relatively scarce [12].

A related issue that should be further addressed is to what extent educational inequalities in NCD incidence 
are mediated by socioeconomic status (SES), other than educational level, and health behaviour. Low income and unstable job statuses, which are likely linked to low educational level, are reasonably predicted to raise the risk of NCD incidence, as documented by previous studies $[2,3]$. Similarly, some types of health behaviours, such as smoking, heavy alcohol drinking, physical inactivity, and unhealthy diet, are expected to mediate the impact of educational level on NCD incidence [1]. To be sure, many studies have assessed the importance of these factors in explaining the educational inequalities in mortality [19-22], worsening frailty [23], and mental health [24]. However, the meditating effects of these factors on educational inequalities in NCD incidence have been largely understudied. If the mediating effects are limited, policy interventions to improve SES or promote healthy lifestyle after the completion of education would not be expected to be effective in moderating educational inequalities in health during later life. Indeed, some studies have provided evidence for the limited mediating effects of SES and health behaviour on worsening frailty [23] and NCD prevalence [18].

It is also interesting to explore gender differences in the association between educational inequalities and NCD incidence. Some studies have found steeper educational gradients in the incidence of some types of NCD among women than among men $[2,5]$. Gender differences may also depend on the type of NCD and there may be also gender differences in contributions of SES and health behaviour in explaining educational inequalities [25].

Considering the obtained knowledge and limitations of the existing literature, the current study conducted a hazards model analysis to examine educational inequalities in NCD incidence, using the 12-wave longitudinal data obtained from nationwide population-based surveys in Japan. The hazards models were estimated for six types of NCDs, and educational inequalities were compared across them. The results are expected to help evaluate the relevance of the observations obtained by preceding prospective cohort and cross-sectional studies. In addition, the extent to which education inequalities in NCD incidence were mediated by SES, other than educational level, and health behaviour was examined. Specifically, household-size adjusted income and job status as well as four types of health behaviour (smoking, heavy alcohol drinking, physical inactivity, and unhealthy diet) at baseline were examined as potential mediators. Furthermore, gender differences in education inequalities were explored.

Japan faces a growing burden of NCDs, while its rate of longevity is one of the highest in the world; NCDs accounted for $54.5 \%$ of total causes of death in 2017, and deaths caused by cancers and heart diseases, the top two causes of death among NCDs, increased from 11.6 and 8.7 per million, respectively, in 1970 to 29.9 and
16.4 per million in 2017 [26]. The increasing burden of NCDs has enhanced the need for health promotion policies to prevent and control NCDs, especially under extended longevity $[27,28]$. The current study focused on the risks of NCDs among middle-aged Japanese, who were 50-59 years old at baseline, given that the prevalence of key NCDs has been shown to increase substantially during the middle age years [26].

\section{Methods \\ Study sample}

Data were obtained from a nationwide, 12-wave panel survey, the Longitudinal Survey of Middle-Aged and Older Adults, conducted by the Japanese Ministry of Health, Labour and Welfare (MHLW) [29] each year from 2005 to 2016. Samples in wave 1 were collected nationwide from individuals between the ages of 50 and 59 years in November 2005, through a two-stage random-sampling procedure. First, 2515 districts were randomly selected from 5280 districts used in the MHLW's nationwide, population-based Comprehensive Survey of the Living Conditions, conducted in 2004. The 5280 districts, in turn, were randomly selected from approximately 940,000 national census districts. Second, depending on the population size of each district, 40, 877 residents, aged 50-59 years as of 30 October 2005, were randomly selected.

The questionnaires were manually delivered to the participants' homes and they were asked to complete them by November 2; the completed questionnaires were collected several days later. A total of 34,240 individuals responded (response rate: 83.8\%). Waves 2-12 of the survey were conducted from 2006 to 2016. The questionnaires of the subsequent waves were only mailed to those participants who had mailed back the completed questionnaires from the previous wave or the one prior to that (average attrition rate of $4.0 \%$ in each wave). No new respondents were added after wave 1 . After removing the respondents missing key variables from the statistical analysis, the responses of 31 , 210 individuals (15,127 men and 16,083 women) were analysed. To capture the educational inequalities in each NCD incidence, the sample used in statistical analysis was further limited to those who did not report the incidence of each disease at the baseline (wave 1). Thus, the number of respondents used for the statistical analysis ranged from 25 , 867 to 30,824, depending on the diseases. The data from the 2005-2014 surveys were used in the corresponding author' previous study [29], and the newly released data from the 2015 and 2016 surveys were additionally used in this study.

\section{Measures \\ NCDs}

Six types of NCDs-diabetes, heart disease, stroke, hypertension, hyperlipidaemia, and cancer-were considered. 
For each NCD, the respondents were asked whether they had been diagnosed with the NCD by a medical doctor at the time of the survey [30]. Although a few examples were presented for some NCDs to the respondents in the survey (e.g. angina and cardiac infarction for heart disease), the experience of diagnosis was self-reported. A binary variable, in which a score of 1 was allocated to the respondents who reported being diagnosed and 0 to others, was constructed.

\section{Educational level}

The survey asked respondents to choose their final educational attainment from among (i) junior high school, (ii) high school, (iii) vocational school, (iv) junior college or technical college, (v) college, (vi) graduate school, and (vii) other. These seven categories were condensed into three levels: 'low' (i), 'middle' (ii, iii, iv, and vii) and 'high' (v and vi), which is standardized categorisation of educational attainment in Japan (e.g. [31-33]). In addition, the ridit score of educational level was derived for each educational level by calculating the mean proportion of the population after ranking it from the highest level to the lowest [34, 35]. For instance, if the respondents with high, middle, and low educational levels comprise $30,50,20 \%$, respectively, of the sample, the ridit-scores for each educational level are calculated as $0.15(0.3 / 2)$ (high), $0.55(0.3+0.5 / 2)$ (middle), and $0.9(0.3+0.5+0.2 / 2)$ (low), respectively, using midpoints for the proportion of the respondents in each level. A higher ridit score corresponds to a lower educational level. This score was used as a continuous variable in the regression analysis.

\section{Baseline SES}

Regarding baseline SES other than educational attainment, household income and job status were considered. As for household income, reported household spending was used as its proxy for three reasons: dependent wives tended to report no income, household spending was expected to represent their standard of living more accurately, and limiting to respondents reporting income reduced the sample size substantially. Household spending was household-size adjusted, by dividing the reported amount by the square root of the number of household members. Then, a binary variable of 'low income' was constructed by allocating a score of 1 to the respondents whose (household size adjusted) household spending belonged to the lowest quartile and 0 to others.

Regarding job status, the respondents were first asked whether they had a paid job, and if they responded 'yes', they were asked to choose their job status from among (i) self-employed, (ii) family worker, (iii) executive of a corporation/organisation, (iv) regular employee, (v) part-time employee, (vi) dispatched employee, (vii) temporary employee, and (viii) engaged in piecework at home, and (ix) other. In this study, the job status was categorised into 'no job,'stable job' (i, iii, iv), and 'unstable' job (ii, v-ix), and 'stable job' was used as a reference category.

\section{Baseline health behaviour}

Four types of health behaviours-smoking, heavy alcohol drinking, physical inactivity, and unhealthy diet-were considered and each of them was expressed as a binary variable. Respondents who answered 'yes' to the question 'Do you smoke currently?' were considered current smokers. Heavy alcohol drinking for men was defined as an intake of more than three go $(540 \mathrm{ml})$ of Japanese sake or an equivalent amount of alcohol every day, which corresponds to about $60 \mathrm{~g}$ of pure alcohol. This threshold was halved for women. These definitions were based on a study that showed that maintaining alcohol consumption below $46 \mathrm{~g} /$ day (for men) and $23 \mathrm{~g} /$ day (for women) appeared to minimise the risks of mortality in a Japanese population [36]. Physical inactivity was defined as engaging in no leisure-time physical activity. Finally, regarding diet, respondents were asked whether they were making an effort on a daily basis to (i) pay attention to the amount of a meal, (ii) eat variety of foods as part of a balanced diet, or (iii) take vitamins or minerals in tablet, capsule, powdered or drinkable form. Unhealthy diet was defined as making none of these efforts.

\section{Covariates}

Age, self-rated health (SRH), and regional areas at the baseline were used as covariates. For age, binary variables for each age were constructed. For SRH, respondents were asked to choose from among 'very good', 'somewhat good', 'somewhat poor,',poor,', and 'very poor' as a response to the question 'What is the current condition of your health?" Binary variables for each response were constructed. Regional areas were included as covariates to account for the potential regional heterogeneity of NCDs and other variables. Binary variables for each of eight areas (Hokkaido, Tohoku, Kanto, Chubu, Kinki, Chugoku, Shikoku, and Kyushu) were used in regression models.

\section{Statistical analysis}

As descriptive analysis, trends in the numbers of respondents who experienced diagnosis of each NCD at any time between waves 2 and 12 across three educational levels were examined. The statistical significance of this trend was evaluated by ' $p$ for trend', based on a chisquare statistic of the trend. In what follows, the trend of health on education - that is, the extent to which the health outcome changes in response to an increase in educational level-is referred to as educational 'gradient' in health.

Following the analysis of variance (ANOVA) to examine the heterogeneity of the prevalence of each $\mathrm{NCD}$ 
across regional areas at baseline, the regression analysis began with examining the association between the ridit score of educational level and each variable of baseline SES and health behaviour-which are considered potential mediators of the impact of educational level in NCD incidence-by logistic regression models, using baseline age and SRH as covariates. The relative index of inequality (RII) by educational level in each outcome was obtained by taking the exponent of the estimated coefficient of the (continuous) ridit score of education in the logistic regression model, in the same way as calculating the odds ratio (OR) of a binary variable $[37,38]$. Thus, the RII indicates the ratio of the odds of each outcome at the lowest educational level (with the ridit score $=1$ ) to those at the highest level (with the ridit score $=0$ ). The RII has been often used to assess educational inequalities in health outcomes by preceding studies $[4,18,24,39]$.

Then, two types of Cox proportional hazards model (Models 1 and 2) were estimated to examine the association between educational level and each NCD incidence. Model 1 explained each NCD incidence solely by the ridit score of educational level, while Model 2 added baseline SES and health behaviour as explanatory variables to Model 1. Both models included baseline ages and SRH as covariates. As with the case of logistic model, the estimated coefficient, if transformed to the hazard ratio (HR), indicates the RII by educational level in NCD incidence. Moreover, the extent of attenuation in the estimated HR from Model 1 to Model 2 indicates how baseline SES and health behaviour jointly mediated the educational inequalities in NCD incidence.

Finally, gender differences in educational inequalities were examined by adding the binary variable for females and its interaction term with the ridit score to Model 2 and using the entire sample. The statistical significance of the estimated HR of the interaction term was used to assess the gender differences.

The software package Stata (Release 15) was used for the statistical analysis [40].

\section{Results}

The key features of the study sample are summarised in Table 1, along with the gender difference and its statistical difference for each variable. Low, middle, and high educational levels comprised $19.4,55.2$, and $25.4 \%$, respectively, for men, and $18.4,74.9$, and $6.7 \%$, respectively, for women, indicating higher educational attainment among men compared to women. The proportion of stable job status was much higher among men (84.2\%) than among women (25.4\%). Women displayed healthier lifestyle than men in all four aspects (smoking, heavy alcohol drinking, physical inactivity, and unhealthy diet).
The prevalence of each NCD over the sample period was compared by educational level in Table 2 . Without controlling for any other factor, an inverse educational gradient was observed for diabetes and stroke among both genders, while such a gradient was observed for heart disease and hypertension only among women. Hyperlipidaemia was positively associated with educational level among both men and women, and cancer was not related to it among either men or women.

The results of the analysis of variance, which tested the null hypothesis that there was no difference in prevalence of each NCD across regional areas, are presented in Table 3 . Judging by the $p$-values, six out of twelve gender-NCD combinations revealed regional heterogeneity. This result indicated the need to control for regional areas in regression analysis.

The estimated RIIs of educational level for baseline SES and health behaviour are summarised in Table 4. To assess the RII of educational level, the estimated OR of each outcome responding to an increase in the ridit score of educational level from 0 (highest) to 1 (lowest) was calculated. Judging by the estimated ORs, lower educational levels were positively associated with low income and unstable job status. The association between lower educational levels and no job was positive for men but negative for women; the latter result probably reflected the existence of highly-educated, dependent wives with no paid job. All four types of unhealthy behaviour were also found to be positively associated with lower educational level; these educational gradients were consistent with the argument that lower SES and unhealthy behaviour can explain educational inequalities in NCD incidence.

Hazards model analysis began by graphically illustrating the Kaplan-Meier survival estimates by educational level in the case of diabetes (without controlling for any other variable). As shown in Fig. 1, the differences in cumulative incidences of diabetes tended to widen as time passed particularly among women. Educational inequalities in the incidence of diabetes were confirmed more formally by Cox proportional hazards models. The estimation results of Models 1 and 2 for diabetes are presented in Table 5. The HRs of the incidence of diabetes in response to an increase in the ridit score of educational level from 0 (highest) to 1 (lowest) (in both Models 1 and 2) as well as to lower SES and unhealthy behaviour (in Model 2) were calculated. The HR for the ridit score indicates the RII by educational level. The estimated HRs were well above one in all model specifications, confirming the inverse educational gradient in the incidence of diabetes, and the gradient was steeper for women than for men.

It was also found that among both men and women, the HRs for the ridit score of educational level was not 
Table 1 Key features of the study sample at baseline

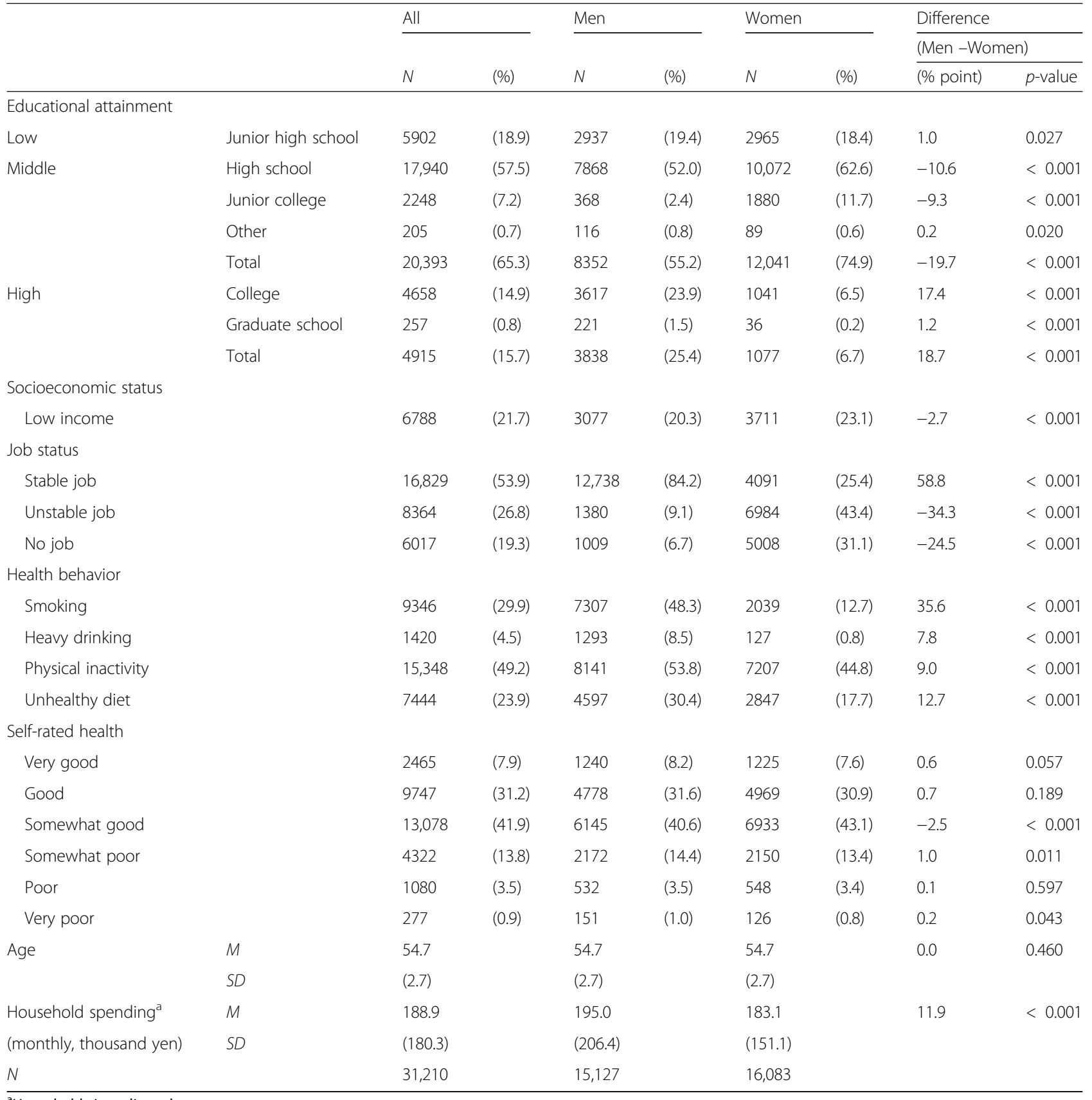

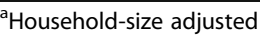

much attenuated and remained highly significant in Model 2, which controlled for baseline SES and health behaviour. Meanwhile, the results of SES and health behaviour in Model 2 were mixed; the incidence was positively associated with smoking, heavy alcohol drinking, and physical inactivity among men and only with no job among women, while no association was observed for any other variable.

Similar Cox proportional hazards models were estimated for other NCDs as well, and their estimated HRs for educational level are summarised in Table 6. Even after controlling for baseline SES and health behaviour, educational inequalities were observed for diabetes and stroke among both men and women and for hypertension only among women. Heart disease and cancer were not associated with educational level, while hyperlipidaemia had a positive association. Only small to moderate parts of the HR were attenuated by baseline SES and health behaviour for NCDs that had inverse educational gradients. When the degree of attenuation was calculated by (HR in Model 
Table 2 Prevalence (\%) of each non-communicable disease over 11-wave, follow-up by educational level

\begin{tabular}{lllllll}
\hline Educational level & All & Low & Middle & High & $p$ for trend & $N$ \\
\hline Men $(N=15,127)$ & & & & & & \\
Diabetes & 13.7 & 15.4 & 14.2 & 11.4 & $<0.001$ & 13,719 \\
Heart disease & 9.7 & 9.8 & 9.7 & 9.5 & 0.687 & 14,581 \\
Stroke & 4.9 & 5.9 & 5.0 & 3.9 & $<0.001$ & 14,886 \\
Hypertension & 32.9 & 32.7 & 33.2 & 32.5 & 0.820 & 12,281 \\
Hyperlipidaemia & 23.8 & 18.0 & 24.0 & 28.0 & $<0.001$ & 13,792 \\
Cancer & 8.6 & 9.1 & 8.6 & 8.3 & 0.237 & 14,931 \\
Women $(N=16,083)$ & & & & & & \\
Diabetes & 8.8 & 13.4 & 8.0 & 5.3 & $<0.001$ & 15,333 \\
Heart disease & 6.0 & 7.1 & 5.8 & 5.8 & $<0.001$ & 15,803 \\
Stroke & 3.2 & 4.3 & 3.0 & 1.7 & $<0.001$ & 15,938 \\
Hypertension & 23.8 & 27.7 & 23.4 & 18.6 & $<0.001$ & 13,586 \\
Hyperlipidaemia & 25.7 & 20.7 & 26.8 & 28.3 & $<0.001$ & 14,706 \\
Cancer & 7.5 & 7.7 & 7.4 & 7.1 & 0.528 & 15,762 \\
\hline
\end{tabular}

$1-$ HR in Model 2) / (HR in Model 1-1) [22], it was in the range between $0.0 \%$ (for hypertension among women) and $32.7 \%$ (for stroke among men). It was also observed that attenuation was more limited among women than among men for diabetes and stroke.

Another noticeable finding was that, as already observed for diabetes in Fig. 1 and Table 5, the estimated HRs for the ridit score of educational level tended to be higher among women than among men for NCDs whose incidences were negatively associated with educational level. To examine gender differences more formally, Table 7 presents the estimated HRs for the ridit score, women, and their intersection terms, obtained by Model 2 using the entire sample. The estimated HR for the intersection term was significantly higher than one for diabetes and hypertension, indicating sharper inverse educational gradients for these diseases among women than among men. The HR for the intersection term was greater than 1 for heart disease, stroke, and hyperlipidaemia, but non-significant.

\section{Discussion}

This study examined educational inequalities in NCD incidence using the data obtained from a 12-wave longitudinal nationwide survey of middle-aged individuals in Japan. Unlike most of the preceding studies, this study applied a hazards model analysis to the data over a long follow-up period (11 years) to capture the association between educational level and NCD incidence. In addition, the potential mediating effects of baseline SES and health behaviour as well as gender differences were explicitly considered. Key findings and their implications are summarised as follows.

First, educational inequalities were confirmed for selected types of NCDs. Even after controlling for baseline SES and health behaviour, Cox proportional hazards model regressions showed that lower educational level was positively associated with the incidences of diabetes and stroke among both men and women, and with hypertension only among women. The observations of the inverse educational gradients were largely consistent with those of preceding studies (for diabetes [2, 10-12, $18]$, stroke [2, 5], and hypertension [2, 13]).

Meanwhile, among both men and women, the incidence of heart disease or cancer had no educational inequalities and the incidence of hyperlipidaemia was positively associated with educational level. Notably, the observed positive association between educational level and hyperlipidaemia was somewhat surprising, but it was consistent with the observation among Korean male adults [41]. One possible reason to explain this result is that higher educational level may lead to a dietary style linked to higher risks of hyperlipidaemia. Indeed, total energy and fat intakes have been found to be positively associated with household expenditure, which is closely linked to educational level, among both male and female adults in Japan [42], possibly because higher-educated, higher-SES individuals have more chances to dine out [41].

Although identifying the reasons to account for the differences across NCDs is beyond the scope of this study, the findings generally underscore the importance of educational level as a key predictor of NCD incidence.

Table 3 Results of the analysis of variance to test the equality of prevalence across eight regional areas ${ }^{\mathrm{a}}$ at baseline for each noncommunicable disease

\begin{tabular}{|c|c|c|c|c|c|c|}
\hline & \multicolumn{3}{|l|}{ Men } & \multicolumn{3}{|l|}{ Women } \\
\hline & F-statistics & $p$-value & $N$ & F-statistics & $p$-value & $N$ \\
\hline Diabetes & 1.21 & 0.293 & 13,719 & 2.64 & 0.010 & 15,333 \\
\hline Heart disease & 1.45 & 0.181 & 14,581 & 0.49 & 0.845 & 15,803 \\
\hline Stroke & 3.31 & 0.002 & 14,886 & 2.03 & 0.048 & 15,938 \\
\hline Hypertension & 1.74 & 0.096 & 12,281 & 1.16 & 0.320 & 13,586 \\
\hline Hyperlipidaemia & 1.56 & 0.141 & 13,792 & 2.10 & 0.041 & 14,706 \\
\hline Cancer & 1.70 & 0.105 & 14,931 & 2.47 & 0.016 & 15,762 \\
\hline
\end{tabular}

aHokkaido, Tohoku, Kanto, Chubu, Kinki, Chugoku, Shikoku, and Kyushu 
Table 4 Estimated associations of educational level with baseline socioeconomic status and health behaviour ${ }^{a}$

\begin{tabular}{|c|c|c|c|c|}
\hline & \multicolumn{2}{|c|}{ Men $(N=15,127)$} & \multicolumn{2}{|c|}{ Women $(N=16,083)$} \\
\hline & $\mathrm{OR}^{\mathrm{b}}(\mathrm{RII})$ & $95 \% \mathrm{Cl}^{\mathrm{c}}$ & OR (RII) & $95 \% \mathrm{Cl}$ \\
\hline \multicolumn{5}{|l|}{ Socioeconomic status } \\
\hline Low income & $3.73^{* * *}$ & $(3.14,4.42)$ & $3.25^{* * *}$ & $(2.72,3.87)$ \\
\hline \multicolumn{5}{|l|}{ Job status } \\
\hline Unstable job & $2.64^{* * *}$ & $(2.10,3.33)$ & $1.98^{* * *}$ & $(1.70,2.30)$ \\
\hline No job & $2.42^{* * *}$ & $(1.83,3.20)$ & $0.82^{*}$ & $(0.70,0.97)$ \\
\hline \multicolumn{5}{|l|}{ Health behaviours } \\
\hline Smoking & $2.80^{* * *}$ & $(2.45,3.21)$ & $2.99^{* * *}$ & $(2.40,3.73)$ \\
\hline Heavy drinking & 1.26 & $(0.99,1.60)$ & $2.79^{*}$ & $(1.24,6.29)$ \\
\hline Physical inactivity & $4.06^{* * *}$ & $(3.54,4.66)$ & $4.18^{* * *}$ & $(3.57,4.88)$ \\
\hline Unhealthy diet & $1.47^{* * *}$ & $(1.28,1.70)$ & $2.29^{* * *}$ & $(1.89,2.77)$ \\
\hline \multicolumn{5}{|c|}{$\begin{array}{l}{ }^{* * *} p<0.001,{ }^{* * *} p<0.01,{ }^{*} p<0.05 \\
\text { adjusted for ages and regional areas at baseline } \\
\text { bOdds ratio. It indicates the relative index of inequality (RII) of } \\
\text { educational level }\end{array}$} \\
\hline
\end{tabular}

To be sure, it cannot be concluded from the results of this study that educational level is a key determinant of NCDs. However, it can be reasonably argued that educational level can be a reliable signal of the risk of the incidences of selected NCDs in later life.

Second, the results revealed that the mediating effects of SES, other than educational attainment, and health behaviour on NCD incidence are relatively limited. Lower income and job status as well as unhealthy behaviour have been found to explain income inequalities in health outcomes [19-22, 24]. Actually, the results showed that lower educational level tended to increase risks of low income, unstable job status, smoking, heavy alcohol drinking, physical inactivity, and unhealthy diet, and that some of these factors modestly raised the risk of NCD incidence. However, inclusion of these factors led to just lowmoderate attenuation in educational inequalities of NCD incidence, a result consistent with the observations in some preceding studies $[18,23]$. This finding suggests that educational attainment as a predictor of NCD incidence is mostly independent of these factors. However, there can be other potential mediators-such as obesity [19], health literacy [43], social participation [23], and accessibility to health care service-that were not considered in this study. Nevertheless, the results point to limited effectiveness of policy interventions to improve SES or promote healthy lifestyle in reducing the educational inequalities in NCD incidence.

Finally, the results showed significant gender differences in educational inequalities in the incidences of diabetes and hypertension. Similar observations have been obtained in preceding studies for diabetes $[2,18]$ and hypertension [2]. The exact reason for these differences and also the reason for no gender differences observed for other diseases were not addressed in this study. However, it might be possible that gender differences in social roles, exposures to stressors, and coping strategies may confound gender differences in educational inequalities in NCD incidence $[44,45]$.

It should be noted that this study had several limitations, besides the observations being limited to middle-

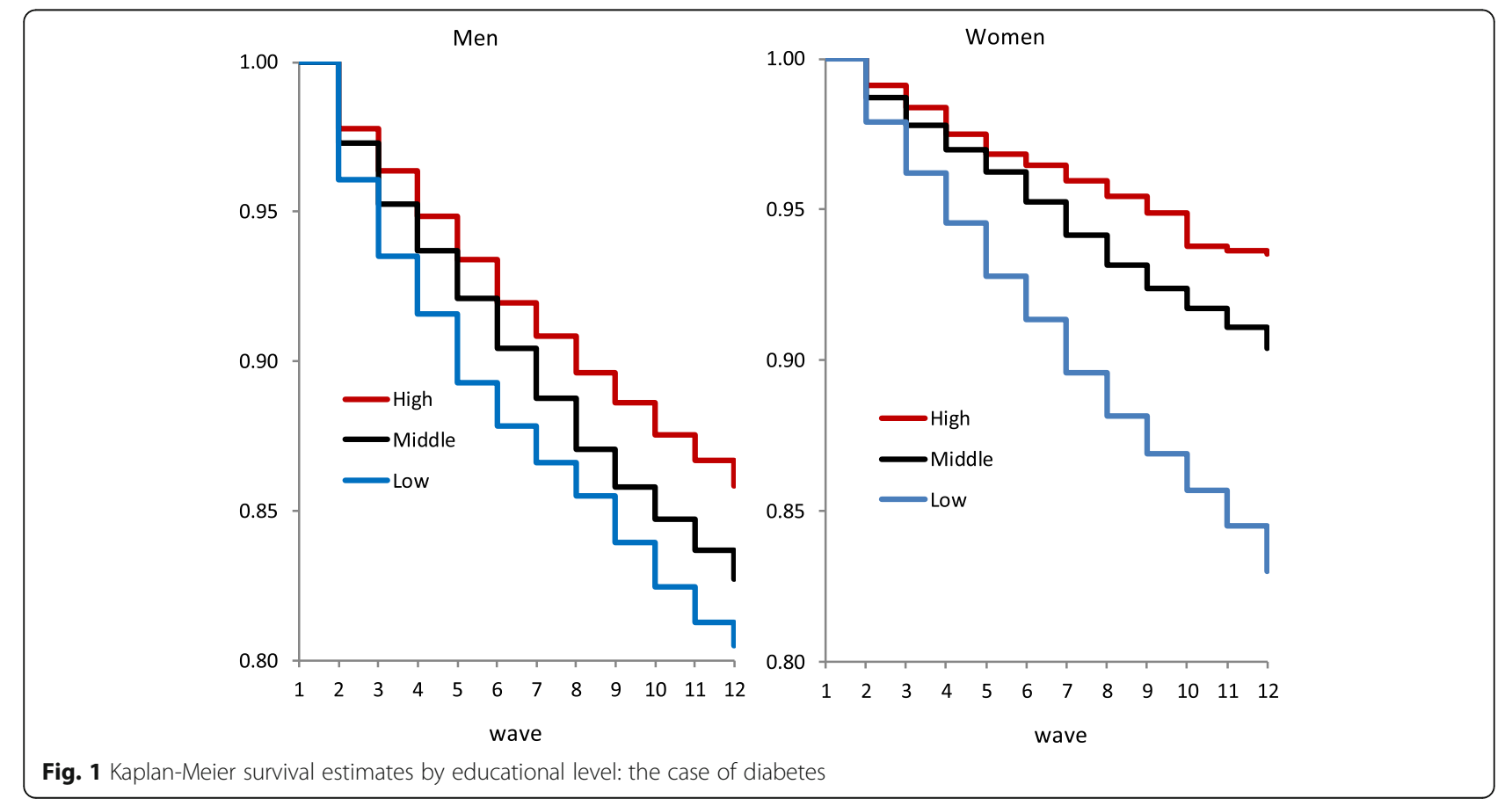


Table 5 Estimated hazard ratios of diabetes for educational level and baseline socioeconomic status and healthy behaviour

\begin{tabular}{|c|c|c|c|c|c|c|c|c|}
\hline & \multicolumn{4}{|c|}{ Men $(N=13,719)$} & \multicolumn{4}{|c|}{ Women $(N=15,332)$} \\
\hline & \multicolumn{2}{|l|}{ Model $1^{a}$} & \multicolumn{2}{|c|}{ Model $2^{b}$} & \multicolumn{2}{|l|}{ Model 1} & \multicolumn{2}{|c|}{ Model 2} \\
\hline & $\overline{H R^{c}}$ & $95 \% \mathrm{Cl}^{\mathrm{d}}$ & $\mathrm{HR}$ & $95 \% \mathrm{Cl}$ & $\mathrm{HR}$ & $95 \% \mathrm{Cl}$ & $\mathrm{HR}$ & $95 \% \mathrm{Cl}$ \\
\hline Ridit score of educational level & $1.49 * * *$ & $(1.25,1.79)$ & $1.41^{* * *}$ & $(1.18,1.70)$ & $2.65^{* * *}$ & $(2.09,3.36)$ & $2.56^{* * *}$ & $(2.01,3.26)$ \\
\hline \multicolumn{9}{|l|}{ Socioeconomic status } \\
\hline Low income & & & 0.96 & $(0.85,1.07)$ & & & 0.97 & $(0.85,1.10)$ \\
\hline \multicolumn{9}{|l|}{ Job status } \\
\hline Unstable job & & & 1.00 & $(0.86,1.18)$ & & & 1.12 & $(0.98,1.29)$ \\
\hline No job & & & 1.09 & $(0.91,1.31)$ & & & $1.17^{*}$ & $(1.01,1.36)$ \\
\hline \multicolumn{9}{|l|}{ Health behaviour } \\
\hline Smoking & & & $1.14^{* *}$ & $(1.04,1.25)$ & & & 1.07 & $(0.91,1.26)$ \\
\hline Heavy drinking & & & $1.23^{* *}$ & $(1.06,1.44)$ & & & 1.08 & $(0.59,1.96)$ \\
\hline Physical inactivity & & & $1.10^{*}$ & $(1.00,1.20)$ & & & 1.05 & $(0.94,1.17)$ \\
\hline Unhealthy diet & & & 0.91 & $(0.83,1.01)$ & & & 1.07 & $(0.94,1.23)$ \\
\hline
\end{tabular}

${ }^{* * *} p<0.001,{ }^{* *} p<0.01,{ }^{*} p<0.05$

${ }^{a}$ Adjusted for ages, self-rated health, and regional areas at baseline

${ }^{b}$ Adjusted for socioeconomic status and health behaviour as well as ages, self-rated health, and regional areas at baseline

${ }^{\mathrm{C}} \mathrm{Hazard}$ ratio. Its value of the ridit score of educational level indicates the relative index of inequality (RII) of educational level

${ }^{\mathrm{d}}$ Confidence interval

aged Japanese people and the reliability of self-reported NCD diagnosis. First, SES and health behaviour of the sample are likely to change across the periods possibly due to health reasons, even though educational attainment can be considered mostly fixed in this study sample. Hence, focusing exclusively on these factors at the baseline may not precisely capture their mediating effects. Second, the results are likely to have been affected by the definitions of health behaviours and other variables. For instance, while physical inactivity was defined as engaging in no leisure-time physical activity in this study, people can be very active in their mainstream life

Table 6 Estimated hazard ratios of each non-communicable disease with respect to educational level

\begin{tabular}{|c|c|c|c|c|c|c|}
\hline & \multicolumn{2}{|c|}{ Model $1^{a}$} & \multicolumn{2}{|c|}{ Model $2^{b}$} & \multirow{2}{*}{$\begin{array}{l}\text { Attenuation } \\
\text { in } \mathrm{HR}(\%)^{\mathrm{e}}\end{array}$} & \multirow[t]{2}{*}{$N$} \\
\hline & $\overline{\mathrm{HR}^{c}}$ & $95 \% \mathrm{Cl}^{\mathrm{d}}$ & $\overline{\mathrm{HR}}$ & $95 \% \mathrm{Cl}$ & & \\
\hline \multicolumn{7}{|l|}{ Men } \\
\hline Diabetes & $1.49^{* * *}$ & $(1.25,1.79)$ & $1.41^{* * *}$ & $(1.18,1.70)$ & 16.3 & 13,719 \\
\hline Heart disease & 0.97 & $(0.79,1.19)$ & 0.94 & $(0.76,1.16)$ & & 14,581 \\
\hline Stroke & $1.55^{* *}$ & $(1.17,2.07)$ & $1.37^{*}$ & $(1.02,1.85)$ & 32.7 & 14,886 \\
\hline Hypertension & 1.00 & $(0.89,1.13)$ & 1.04 & $(0.91,1.17)$ & & 12,281 \\
\hline Hyperlipidaemia & $0.55^{* * *}$ & $(0.48,0.63)$ & $\begin{array}{l}0.61 \\
* * *\end{array}$ & $(0.53,0.71)$ & & 13,792 \\
\hline Cancer & 1.14 & $(0.92,1.42)$ & 1.14 & $(0.92,1.43)$ & & 14,931 \\
\hline \multicolumn{7}{|l|}{ Women } \\
\hline Diabetes & $2.65^{* * *}$ & $(2.09,3.36)$ & $2.56^{* * *}$ & $(2.01,3.26)$ & 5.5 & 15,333 \\
\hline Heart disease & 1.12 & $(0.83,1.50)$ & 1.10 & $(0.82,1.48)$ & & 15,803 \\
\hline Stroke & $1.97^{* * *}$ & $(1.33,2.91)$ & $1.84^{* *}$ & $(1.24,2.75)$ & 12.4 & 15,938 \\
\hline Hypertension & $1.48^{* * *}$ & $(1.26,1.73)$ & $1.48^{* * *}$ & $(1.26,1.74)$ & 0.0 & 13,586 \\
\hline Hyperlipidaemia & $0.59^{* * *}$ & $(0.51,0.69)$ & $0.64^{* * *}$ & $(0.55,0.75)$ & & 14,706 \\
\hline Cancer & 1.05 & $(0.80,1.37)$ & 1.07 & $(0.81,1.40)$ & & 15,762 \\
\hline
\end{tabular}

*** $p<0.001,{ }^{* *} p<0.01,{ }^{*} p<0.05$

${ }^{a}$ Adjusted for ages, self-rated health, and regional areas at baseline

${ }^{b}$ Adjusted for socioeconomic status and health behaviour as well as ages, self-rated health, and regional areas at baseline

${ }^{c}$ Hazard ratio. It indicates the relative index of inequality (RII) of educational level

${ }^{\mathrm{d} C o n f i d e n c e ~ i n t e r v a l ~}$

e (HR in Model $1-$ HR in Model 2)/(HR in Model 1-1) $\times 100 \%$ 
Table 7 Estimated hazard rates of each non-communicable disease for educational level, using the entire sample ${ }^{a}$

\begin{tabular}{|c|c|c|c|c|c|c|c|}
\hline & \multicolumn{2}{|c|}{ Ridit score of educational level } & \multicolumn{2}{|l|}{ Females } & \multicolumn{2}{|c|}{ Ridit score of educational level $\times$ Females } & \multirow[t]{2}{*}{$N$} \\
\hline & $\overline{\mathrm{HR}^{\mathrm{b}}(\mathrm{RII})}$ & $95 \% \mathrm{Cl}^{\mathrm{C}}$ & $\overline{\mathrm{HR}}$ & $95 \% \mathrm{Cl}$ & $\overline{\mathrm{HR}}$ & $95 \% \mathrm{Cl}$ & \\
\hline Diabetes & $1.37^{* * *}$ & $(1.14,1.64)$ & $0.41^{* * *}$ & $(0.34,0.50)$ & $2.01^{* * *}$ & $(1.50,2.69)$ & 29,051 \\
\hline Heart disease & 0.91 & $(0.74,1.12)$ & $0.58^{* * *}$ & $(0.47,0.72)$ & 1.28 & $(0.90,1.81)$ & 30,383 \\
\hline Stroke & $1.38^{*}$ & $(1.03,1.84)$ & $0.55^{* * *}$ & $(0.41,0.74)$ & 1.35 & $(0.84,2.17)$ & 30,823 \\
\hline Hypertension & 1.01 & $(0.90,1.14)$ & $0.54^{* * *}$ & $(0.48,0.61)$ & $1.51^{* * *}$ & $(1.24,1.84)$ & 25,866 \\
\hline Hyperlipidaemia & $0.60^{* * *}$ & $(0.53,0.69)$ & 1.02 & $(0.91,1.14)$ & 1.10 & $(0.90,1.34)$ & 28,497 \\
\hline Cancer & 1.16 & $(0.93,1.44)$ & 1.02 & $(0.83,1.24)$ & 0.90 & $(0.64,1.26)$ & 30,692 \\
\hline
\end{tabular}

${ }^{* * *} p<0.001,{ }^{* *} p<0.01,{ }^{*} p<0.05$

${ }^{a}$ Adjusted for socioeconomic status, health behaviour as well as ages, self-rated health, and regional areas at baseline

${ }^{b}$ Hazard ratio. Its value of the ridit score of educational level indicates the relative index of inequality (RII) of educational level

${ }^{c}$ Confidence interval

without engaging in leisure-time physical activity. Third, as mentioned above, there are potentially other mediators than those of SES and health behaviour considered in this study for educational inequalities in NCD incidence. Adding these factors in the analysis, the attenuation of estimated educational inequalities from Model 1 to Model 2 may be reduced, possibly affecting the interpretation regarding the degree of independent impact of educational level on NCD incidence. Fourth, respondents who dropped out without incidence were censored in each regression model, as is usually the case of hazards model analysis. Although the average attrition rate was as low as $4 \%$ in each wave, neglecting the possibility of the attrition due to the incidence may have led to an underestimation of the risk of incidence.

\section{Conclusions}

This study underscores educational inequalities in the incidences of selected NCDs, especially among women. Inverse educational gradient in NCD incidence was not much attenuated by adjusting for mediating effects of baseline SES and health behaviour. Further analysis is needed to identify the mechanism linking educational level and incidences of each specific NCD. Still, the observation that educational level was associated with $\mathrm{NCD}$ incidence in a relatively non-mediated manner has important implications for public health. Educational level can be utilized as a reliable signal of the risk of NCD incidence in general, suggesting that the policy measures to reduce such a risk should be targeted to individuals with lower educational level. It can be also argued that policy support to help socioeconomically disadvantaged children to enhance educational attainment is recommended to reduce inequality in health in later life.

\section{Abbreviations}

HR: Hazard ratio; MHLW: Ministry of Health, Labour and Welfare; NCD: Noncommunicable diseases; OR: Odds ratio; Rll: Relative index of inequality; SES: Socioeconomic status; SRH: Self-rated health

\section{Acknowledgements}

This study was supported by the Joint Usage and Research Center, Institute of Economic Research, Hitotsubashi University.

\section{Authors' contributions}

The dataset was constructed by MK, analyses were performed by TO, and the initial manuscript was prepared by TO in cooperation with MK. The final manuscript was read and approved by all authors.

\section{Funding}

This study was financially supported by a grant from the Japan Society for the Promotion of Science (JSPS) (Grant Numbers: $17 \mathrm{H} 00991$ and 18 K01657). The funding body had no role in the design of the study, in the collection, analysis and interpretation of the data, or in writing the manuscript.

\section{Availability of data and materials}

The data that support the findings of this study are available from the MHLW but restrictions apply to the availability of these data, which were used under licence for the current study, and so are not publicly available. Data are, however, available from the authors upon reasonable request and with permission of the MHLW.

\section{Ethics approval and consent to participate}

Data that were obtained from the Longitudinal Survey of Middle-Aged and Older Adults, a 12-wave panel survey, conducted by the Japanese MHLW each year between 2005 and 2016, were used. This survey was approved by Japan's Statistics Act, which required that it be reviewed from statistical, legal, ethical, and other viewpoints. Survey data were obtained from the MHLW, with its official permission. Therefore, the current study did not require ethical approval. The need for written consent was waived, in line with the Statistics Act.

\section{Consent for publication}

Not applicable.

\section{Competing interests}

The authors declare that they have no competing interests.

\section{Author details}

'Institute of Economic Research, Hitotsubashi University, 2-1 Naka, Kunitachi, Tokyo 186-8603, Japan. ${ }^{2}$ School of Economics, University of Hyogo, 8-2-1 Gakuen-Nishi-machi, Nishi-ku, Kobe, Hyogo 651-2197, Japan.

Received: 27 January 2019 Accepted: 17 June 2019

Published online: 01 July 2019

\section{References}

1. World Health Organization. Health 2020: education and health through the life-course. http://www.euro.who.int/_data/assets/pdf_file/0007/324619/ Health-2020-Education-and-health-through-the-life-course-en.pdf?ua=1 . Accessed 20 Jan 2019. 
2. Dalstra JA, Kunst AE, Borrell C, Breeze E, Cambois E, Costa G, et al. Socioeconomic differences in the prevalence of common chronic diseases: an overview of eight European countries. Int J Epidemiol. 2005;34:316-26. https://doi.org/10.1093/ije/dyh386.

3. Sommer I, Griebler U, Mahlknecht P, Thaler K, Bouskill K, Gartlehner G, et al. Socioeconomic inequalities in non-communicable diseases and their risk factors: an overview of systematic reviews. BMC Public Health. 2015;15:914. https://doi.org/10.1186/s12889-015-2227-y.

4. Ernstsen L, Strand BH, Nilsen SM, Espnes GA, Krokstad S. Trends in absolute and relative educational inequalities in four modifiable ischaemic heart disease risk factors: repeated cross-sectional surveys from the NordTrøndelag health study (HUNT) 1984-2008. BMC Public Health. 2012;12:266. https://doi.org/10.1186/1471-2458-12-266.

5. Jackson CA, Sudlow CLM, Mishra GD. Education, sex and risk of stroke: a prospective cohort study in New South Wales, Australia. BMJ Open. 2018;8: e024070. https://doi.org/10.1136/bmjopen-2018-024070.

6. Janković S, Stojisavljević D, Janković J, Erić M, Marinković J. Association of socioeconomic status measured by education, and cardiovascular health: a population-based cross-sectional study. BMJ Open. 2014;4:e005222. https:// doi.org/10.1136/bmjopen-2014-005222.

7. Kubota Y, Heiss G, MacLehose RF, Roetker NS, Folsom AR. Association of educational attainment with lifetime risk of cardiovascular disease: the atherosclerosis risk in communities study. JAMA Intern Med. 2017;177:116572. https://doi.org/10.1001/jamainternmed.2017.1877.

8. Sidorchuk A, Agardh EE, Aremu O, Hallqvist J, Allebeck P, Moradi T. Socioeconomic differences in lung cancer incidence: a systematic review and meta-analysis. Cancer Causes Control. 2009;20:459-71. https://doi.org/ 10.1007/s10552-009-9300-8

9. Uthman OA, Jadidi E, Moradi T. Socioeconomic position and incidence of gastric cancer: a systematic review and meta-analysis. J Epidemiol Community Health. 2013;67:854-60. https://doi.org/10.1136/jech-2012201108

10. Agardh E, Allebeck P, Hallqvist J, Moradi T, Sidorchuk A. Type 2 diabetes incidence and socio-economic position: a systematic review and metaanalysis. Int J Epidemiol. 2011;40:804-18. https://doi.org/10.1093/ije/dyr029.

11. Lee TC, Glynn RJ, Peña JM, Paynter NP, Conen D, Ridker PM, et al. Socioeconomic status and incident type 2 diabetes mellitus: data from the Women's health study. PLoS One. 2011;6:e27670. https://doi.org/10.1371/ journal.pone.0027670.

12. Stringhini $S$, Batty GD, Bovet $P$, Shipley MJ, Marmot MG, Kumari M, et al. Association of lifecourse socioeconomic status with chronic inflammation and type 2 diabetes risk: the Whitehall II prospective cohort study. PLoS Med. 2013;10:e1001479. https://doi.org/10.1371/journal.pmed.1001479.

13. Leng B, Jin Y, Li G, Chen L, Jin N. Socioeconomic status and hypertension: a meta-analysis. J Hypertens. 2015;33:221-9. https://doi.org/10.1097/HJH. 0000000000000428.

14. Eagan TM, Gulsvik A, Eide GE, Bakke PS. The effect of educational level on the incidence of asthma and respiratory symptoms. Respir Med. 2004;98: 730-6. https://doi.org/10.1016/j.rmed.2004.02.008.

15. Kunst AE, Mackenbach JP. The size of mortality differences associated with educational level in nine industrialized countries. Am J Public Health. 1994; 84:932-7. https://doi.org/10.2105/AJPH.84.6.932.

16. Lleras-Muney A. The relationship between education and adult mortality in the United States. Rev Econ Stud. 2005;72:189-221. https://doi.org/10.1111/ 0034-6527.00329.

17. Montez JK, Hummer RA, Hayward MD. Educational attainment and adult mortality in the United States: a systematic analysis of functional form. Demography. 2012;49:315-36. https://doi.org/10.1007/s13524-011-0082-8.

18. Kim GR, Nam CM. Temporal trends in educational inequalities in noncommunicable diseases in Korea, 2007-2015. PLoS One. 2017;12:e0190143. https://doi.org/10.1371/journal.pone.0190143. eCollection 2017.

19. Kulhánová I, Menvielle G, Hoffmann R, Eikemo TA, Kulik MC, Toch-Marquardt $M$, et al. The role of three lifestyle risk factors in reducing educational differences in ischaemic heart disease mortality in Europe. Eur J Pub Health. 2017;27:203-10. https://doi.org/10.1093/eurpub/ckw104.

20. Skalická V, van Lenthe F, Bambra C, Krokstad S, Mackenbach J. Material, psychosocial, behavioural and biomedical factors in the explanation of relative socio-economic inequalities in mortality: evidence from the HUNT study. Int J Epidemiol. 2009;38:1272-84. https://doi.org/10.1093/ije/dyp262.

21. Schrijvers CT, Stronks K, van de Mheen HD, Mackenbach JP. Explaining educational differences in mortality: the role of behavioral and material factors. Am J Public Health. 1999;89:535-40. https://doi.org/10.2105/ AJPH.89.4.535.

22. Stringhini S, Dugravot A, Shipley M, Goldberg M, Zins M, Kivimäki M, et al. Health behaviours, socioeconomic status, and mortality: further analyses of the British Whitehall II and the French GAZEL prospective cohorts. PLoS Med. 2011;8:e1000419. https://doi.org/10.1371/journal.pmed.1000419.

23. Etman A, Kamphuis CB, van der Cammen TJ, Burdorf A, van Lenthe FJ. Do lifestyle, health and social participation mediate educational inequalities in frailty worsening? Eur J Pub Health. 2015;25:345-50. https://doi.org/10.1093/ eurpub/cku093.

24. Katikireddi SV, Niedzwiedz CL, Popham F. Employment status and income as potential mediators of educational inequalities in population mental health. Eur J Pub Health. 2016;26:814-6. https://doi.org/10.1093/ eurpub/ckw126.

25. van Hedel K, van Lenthe FJ, Oude Groeniger J, Mackenbach JP. What's the difference? A gender perspective on understanding educational inequalities in all-cause and cause-specific mortality. BMC Public Health. 2018;18:1105. https://doi.org/10.1186/s12889-018-5940-5.

26. Ministry of Health, Labour and Welfare. Vital Statistics. https://www.mhlw.go. jp/toukei/list/81-1.html. Accessed 15 Apr 2019.

27. Ezoe S, Noda H, Akahane N, Sato O, Hama T, Miyata T, et al. Trends in policy on the prevention and control of non-communicable diseases in Japan. Health Syst Reform. 2017;3:268-77. https://doi.org/10.1080/23288604.2017. 1347125.

28. Wu F, Narimatsu H, Li X, Nakamura S, Sho R, Zhao G, et al. Noncommunicable diseases control in China and Japan. Glob Health. 2017;13: 91. https://doi.org/10.1186/s12992-017-0315-8.

29. Oshio T. Widening disparities in health between educational levels and their determinants in later life: evidence from a nine-year cohort study. BMC Public Health. 2018;18:278. https://doi.org/10.1186/s12889-018-5181-7.

30. Ministry of Health, Labour and welfare. Longitudinal survey of middleaged and older adults. https://www.mhlw.go.jp/toukei/list/29-6.html. Accessed 15 Apr 2019.

31. Imanishi $Y$, Fukuma $S$, Karaboyas A, Robinson BM, Pisoni RL, Nomura $T$, et al. Associations of employment status and educational levels with mortality and hospitalization in the dialysis outcomes and practice patterns study in Japan. PLoS One. 2017;12:e0170731. https://doi.org/10. 1371/journal.pone.0170731.

32. Ota A, Yatsuya H, Nishi N, Okuda N, Ohkubo T, Hayakawa T, et al. Relationships among socioeconomic factors and self-rated health in Japanese adults: NIPPON DATA 2010. J Epidemiol. 2018;28(Suppl 3):S66-72. https://doi.org/10.2188/jea.JE20170246.

33. Tomioka K, Kurumatani N, Saeki K. The association between education and smoking prevalence, independent of occupation: a nationally representative survey in Japan. J Epidemiol. 2019. https://doi.org/10.2188/jea.JE20180195 Epub ahead of print

34. Brockett PL, Levine A. On a characterization of ridits. Ann Stat. 1977:5:12458. https://doi.org/10.1214/aos/1176344010.

35. Bross IDJ. How to use ridit analysis. Biometrics. 1958;14:18-38. https://doi. org/10.2307/2527727.

36. Inoue M, Nagata C, Tsuji I, Sugawara Y, Wakai K, Tamakoshi A, et al. Impact of alcohol intake on total mortality and mortality from major causes in Japan: a pooled analysis of six large-scale cohort studies. J Epidemiol Community Health. 2012;66:448-56. https://doi.org/10.1136/jech.2010.121830.

37. Moreno-Betancur M, Latouche A, Menvielle G, Kunst AE, Rey G. Relative index of inequality and slope index of inequality: a structured regression framework for estimation. Epidemiology. 2015;26:518-27. https://doi.org/10. 1097/EDE.0000000000000311.

38. Sergeant JC, Firth D. Relative index of inequality: definition, estimation, and inference. Biostatistics. 2006;7:213-24. https://doi.org/10.1093/ biostatistics/kxj002.

39. Cavelaars AE, Kunst AE, Geurts JJ, Crialesi R, Grötvedt L, Helmert U, et al. Differences in self reported morbidity by educational level: a comparison of 11 western European countries. J Epidemiol Community Health. 1998;52: 219-27. https://doi.org/10.1136/jech.52.4.219.

40. StataCor. Stata Statistical Software: Release 15. College Station: StataCorp LLC; 2017.

41. Nam GE, Cho KH, Park YG, Han KD, Choi YS, Kim SM, et al. Socioeconomic status and dyslipidemia in Korean adults: the 2008-2010 Korea National Health and Nutrition Examination Survey. Prev Med. 2013;57:304-9. https:// doi.org/10.1016/j.ypmed.2013.06.008. 
42. Fukuda Y, Hiyoshi A. High quality nutrient intake is associated with higher household expenditures by Japanese adults. Biosci Trends. 2012;6:176-82.

43. Mantwill S, Monestel-Umaña S, Schulz PJ. The relationship between health literacy and health disparities: a systematic review. PLoS One. 2015;10: e0145455. https://doi.org/10.1371/journal.pone.0145455.

44. Denton M, Prus S, Walters V. Gender differences in health: a Canadian study of the psychosocial, structural and behavioural determinants of health. Soc Sci Med. 2004;58:2585-600. https://doi.org/10.1016/.socscimed.2003.09.008.

45. McDonough P, Walters V. Gender and health: reassessing patterns and explanations. Soc Sci Med. 2001;52:547-5. https://doi.org/10.1016/S02779536(00)00159-3.

\section{Publisher's Note}

Springer Nature remains neutral with regard to jurisdictional claims in published maps and institutional affiliations.

Ready to submit your research? Choose BMC and benefit from:

- fast, convenient online submission

- thorough peer review by experienced researchers in your field

- rapid publication on acceptance

- support for research data, including large and complex data types

- gold Open Access which fosters wider collaboration and increased citations

- maximum visibility for your research: over $100 \mathrm{M}$ website views per year

At $\mathrm{BMC}$, research is always in progress.

Learn more biomedcentral.com/submissions 